\title{
IMPLEMENTATION OF EDUCATIONAL REFORMS DURING THE 1990s IN POLAND: OBSTACLES AND CONDITIONS
}

\author{
Yuliia Hryshchuk \\ ORCID iD 0000-0002-5306-0301 \\ research worker of Scientific-Research Laboratory of Educology \\ Borys Grinchenko Kyiv University \\ 13-b Tymoshenko Str., 04212 Kyiv, Ukraine \\ y.hryshchuk@kubg.edu.ua
}

\section{ABSTRACT}

The article describes the main directions of educational reforms during the 1990ies in Poland; analyzed the structure of the educational system in Poland; examined changes being implemented in the system of training teachers; identified obstacles and conditions for implementing reforms during transition period.

Key words: educational reforms; structure of the educational system; teacher training.

\section{INTRODUCTION}

The basic assumption of educational reforms carried out in Poland, during the 1990s, was the departure from an overly standardized educational system. Introduced changes were to allow teachers to decide individually about the ways of carrying out prescribed educational programs (basic programs), to extensively include parents and local communities in decisions pertaining to life of the school (parents' councils, non-public schools) and to improve correlation of vocational education with needs of the labour market during conditions of economic transformation. At the same time, it was necessary to safeguard the basic characteristic of the education system - its general accessibility. This goal is to be served by the mandatory schooling and by keeping education as free-of-charge (in the basic extent of the program) - from pre-school to university. Care for the education system's flexibility and proper composition of the school network are also of significant importance (Development of education in Poland in 1992-1993, 1994, p. 14).

The purpose of the article is to study the main directions of educational reforms during the 1990-ies in Poland and analyze the obstacles and the conditions for their implementation.

Law «About school higher education» on September 12, 1990, provided the opportunity to enter the public universities in payment for the provision of certain educational services (correspondence and evening education and postgraduate training). After the collapse of the socialist system in the education system in Poland is the reorientation the educational standards in industrialized countries in Europe (Hromov, 2010).

The directions of the policy of the Ministry of Public Education in 1991 were characterized as follows: the expansion of the study of one foreign language in basic schools and two foreign languages in secondary schools; recognition of the position 
of English as a universal means of international communication; the promotion of intensive courses and the early learning of a foreign language by children. The Ministry has identified a long-term goal: $100 \%$ of society knows at least one foreign language, and 60\% - two (Komorowska,1991).

New systemic resolutions - such as taking over of responsibility for maintaining and conducting of schools by local authorities - must take into account the possibilities of eruption of negative situations connected with remodeling of the system, such as decreasing of education establishments, worsening of work conditions for teachers and also transfer of educational costs, in constantly increasing degrees, unto parents. Reform activities, continued in the years 19921993, had proceeded on many levels and at various speeds. As the most important during that period, we consider efforts toward restructurization of vocational education, further modernization of educational subjects and methods and continuation of the process of creating new legal framework for the education system. Among the priorities of the reform, there remained changes in the system of educating and improving qualifications of teachers. The changing socio-economical conditions have drawn with them the attempt at a new approach to the matters of adult education and non-formal education (Development of education in Poland in 1992-1993, 1994, p. 14).

As a result of the reform, autonomy of educational institutions, their initiative has considerably expanded. According to the program reform, the teacher can choose or programs recommended by the Ministry of Public Education (and they were approved by the beginning of the reform more than 320 : for $1-3$ for classes54; 4-6 - 112 and high schools - 158), or can use their own copyright programs. This should help to better use the teaching staff (Pendel, 2003).

\section{STRUCTURE OF THE EDUCATIONAL SYSTEM IN POLAND, DURING THE YEARS 1992-1993}

Structure of the educational system in Poland, during the years 1992-1993, has not changed significantly in respect to previous years.

In accordance with the Legislative Act of September 7, 1991, the educational system in Poland has the following structure (Development of education in Poland in 1992-1993, 1994, p. 3): pre-schools, including special type; primary schools and secondary schools, excluding higher education schools of all types, also special and art education schools; educational and youth training centers which foster development of special interests and predispositions, attainment of complementary knowledge and acquirement of skills as well as taking advantage of various forms of recreation, in this, organized recreation outside the place of residence/ summer camps, youth camps/ and at the place of residence; guidance centers of the psychological and pedagogical type, as well as other special guidance centers offering psychological and pedagogical assistance to children, youths, parents and teachers, and also providing direction to pupils in their selection of educational avenue and vocation; guardian-upbringing centers and re-socializing centers which provide education, upbringing and care for children and youngsters, going to school, who are deprived of parental care, partially or totally; substitute families; adoption and care centers which initiate and assist with substitute forms of family upbringing; centers for training and in-service training of teachers; pedagogical libraries. 


\section{TEACHERS' TRAINING}

In the school year 1992/93, there was a total of 640000 teachers working in education / in this, 546000 had full-time employment. In this number, 60,3\% teachers had higher education diplomas; 27,5\% of them had graduated from Teachers Study Program / 2 year, post-matriculation school, non-existent anymore; the remaining - about 13\%, had secondary school education. The present state and perspectives ahead of the teachers' training system: sub-system of orientation and selection for the teachers' profession; sub-system of teachers' training; sub-system of in-service training (Development of education in Poland in 1992-1993, 1994, p. 16).

Orientation and selection for the profession. The main element of the subsystem of orientation and selection for the teachers' profession are institutional activities which are directed toward systematic presentation, to the pupils, of psychological and pedagogical knowledge and organizing practical sessions which are conducive to operative application of this knowledge in school situations. Among the didactic forms which make possible a most extensive implementation of this type of activities, we differentiate (Development of education in Poland in 1992-1993, 1994, p. 16): 1) introduction of classes or secondary schools with profiled programs, in which during the 4 years of learning, the pupils become acquainted with pedagogical theories and attain knowledge about practical aspects of the vocation; 2) facultative classes, in psychology and pedagogics, in general secondary schools, which develop interests and promote motivation to undertake pedagogical studies and other studies which prepare for the teachers' vocation.

A supplement to the institutional activities are, similarly as in the case of other vocations, activities which consist of sporadic information service to the pupils about specifics of the teachers' vocation and the necessary preparations toward it. Orientation of the occasional type is dominant, unfortunately, and becomes the cause of selecting the way of life by chance, and also influences the so called negative selection. Improper vocational orientation and conventional entrance exams to higher education schools which train future teachers are the cause of frequent occurrence of cases where students do not have the predispositions for this vocation and in consequence, do not undertake work in school after completing their education (Development of education in Poland in 1992-1993, 1994, p. 17).

\section{CHANGES BEING IMPLEMENTED IN THE SYSTEM OF TRAINING TEACHERS}

As of 1990, a new form of teachers' training has been enacted - three-year teachers' colleges. These colleges, both public and non-public, train teachers of foreign languages (English, French, German) for various types of schools and teachers of general education classes and other subjects for primary schools (such as: Polish language, math, initial teaching with logopedics). During the 1992/93 school year, teachers' colleges graduated over 2000 foreign language teachers. These colleges are closely integrated with universities and higher pedagogy schools, which provide them with meritorious supervision. A declaration of intent to provide such supervisions is the basic requisite for establishing such a college (Development of education in Poland in 1992-1993, 1994, p. 19). 
An innovation of the training system in these colleges is placement of particular stress on practical training-practice provides the necessary context for acquisition of pedagogic qualifications. Besides the organized practice, an integral part of training is the personal educative experience of the student (listener). A form of implementing capabilities training are, the so called, workshops of didactic and tutorial capabilities. Significant help in up-dating subject matter and methods of education and in-service training may be derived from educative programs implemented with the aid of foreign assistance. Changes taking place at university training of teachers are the effect of autonomy attained by schools of higher education; these take on various forms. It must be stated that the participation of universities in training teachers with complete qualifications/subject specializations and pedagogy/ is decreasing, even though this does not pertain to all schools and specializations of study. Pedagogic training is being phased out at the departments of philology of foreign languages / English, Romanesque, German. Along side the process of closing down pedagogic training courses, the process of limiting them may also be observed. Particular universities are departing from the minimum program of 90 hours of pedagogy, 90 hours of psychology and 120 hours of teaching methodology for the particular subject of specialization (Development of education in Poland in 1992-1993, 1994, p. 20).

The existing form of training and in-service training of teachers were supplemented by educational programs in the mass media. Among these was the Teachers' University on the Radio and Television, active since 1974, it was an institutional form of multi-media training at a distance, through radio, television, video case and printed material. These programs were aired on the nationwide network through Polish Radio, 5 times a week, and through Polish National Television, 3 times a week. In connection with sociopolitical, economic and cultural changes, these programs were modified in recent years. During the years 1990-1991, these were programs referring to a variety of subjects, encompassing many disciplines of contemporary science and practical teaching activities in the new educative situation (Development of education in Poland in 1992-1993, 1994, p. 21-23).

In 1999 additional changes regarding teachers and governance were introduced. A new system of teacher development was established with four professional levels. The system created incentives to improve teaching, although it was also criticized as being too bureaucratic. In fact, the system was used to increase teacher salaries with each level providing better remuneration. Between 2006 and 2012 salaries at all levels were increased by $50 \%$ on average. The largest increase was for the youngest teachers, to limit negative selection into the profession. In 1999 the governance and finance system was also further decentralized. Currently local governments are partly responsible for financing education, although most of the funds are transferred from the central budget. In addition, the main expenditure is teacher salaries and those are centrally regulated to a large degree, according to the professional levels scheme. In any case, local governments are adding more than $20 \%$ of the funds from their own resources and are responsible for the increased investment in school facilities (Jakubowski, 2015). 


\section{OBSTACLES AND CONDITIONS FOR IMPLEMENTING REFORMS DURING TRANSITION PERIOD}

First four years of functioning of the education system in the new political and economic conditions brought the opening of new possibilities for implementation of new educational and pedagogic concepts. At the same time, previously existing material difficulties of educational institutions have deepened. The fast economic transformations were accompanied by a decrease of income into the state budget, which had drastic effects on financing education, health care and culture.

It is estimated that during these four years, expenditures from the state budget directed to education had decreased by about 30\%. This had a negative effect on the material situation of schools and the livelihood of teachers (average wages in this profession did not exceed $80 \%$ of the national average wage). Decreased budget subsidy is compensated, only to some degree, by self-financing activities of schools (introduction of fees for some courses, facultative classes, etc.). Development of community and private schools, financed by teachers to a significant degree and various types of organizations and associations, also meets obstacles: among the population, there are few really rich people and living conditions of most Poles still are not easy. Financial difficulties caused disagreement between the intent to transfer the responsibilities for managing schools to local self-government authorities (communities (gminy)) and the economic capacities of the latter. Even through it is true that in the 300 communities in which the local self-government authorities took over the management of their schools, the situation of these school had improved markedly, still the remaining 2000 communities cannot offer equivalent conditions. It is for this reason that in the second half of 1994, the Polish Parliament (Sejm) had passed a legislative correction, to the obligatory Legislative Act about the education system, in which it postponed the estimated deadline for obligatory take-over of primary schools by the communities, by 2 years, till January 1, 1996. A warning against the effects of excessively fast decentralization of educational administration is presented by the fate of pre-schools, which had been transferred to community management in 1990. During the years 1990-1992, the number of pre-school centers had decreased from 26042 to 21164. During this period, almost 15 thousand pre-school teachers lost their jobs (Development of education in Poland in 1992-1993, 1994, p. 26).

Assessing the success of educational reforms in the period of the transformation of the political and economic system in Poland is worth taking into account the political factor. During 1992-1993 there were three changes in the ruling coalition. The gradual implementation of the concept of educational reforms, which began in 1990, did not contribute to accelerating parliamentary elections. However, we have grounds to argue that educational reforms were inherently progressive and contributed to the development of pedagogical education in accordance with European standards.

\section{CONCLUSIONS}

The beginning of the 90 's of the twentieth century can be regarded as a period of social and economic crises and transformation of Polish society. The political breakthrough that has taken place in Poland in this period has opened the way for change to the country, namely the fundamental transformation of political, 
economic and social systems. The first years of the functioning of the education system in the new political and economic conditions opened up opportunities for the introduction of innovative educational and pedagogical concepts. At the same time, previously existing financial difficulties of educational institutions have deepened. Rapid economic transformations were accompanied by a decrease in revenues to the state budget, which significantly influenced the financing of education, health and culture.

It is worth noting that, one of the main factors in the beginning of transformation were the European aspirations of Poland and the prospect of joining the European Union. Integration into the European Community was demanded from Poland to implement a wide range of reforms in all spheres of public life aimed at achieving the standards of the European Union.

\section{REFERENCES}

Development of education in Poland in 1992-1993 (1994, August). International conference on education. 44-th Session, Geneva 1994. Report prepared by Ministry of National Education in the Republic of Poland. Warsaw, Poland, 33.

Hromov, Ye. V. (2010). Modern trends in vocational education in Poland. Extended abstract of candidate's thesis. Vinnytsia, Ukraine.

Jakubowski, M. (2015). Opening up opportunities: education reforms in Poland. IBS Policy Paper, 1.

Komorowska, H. (1991). Language Teaching and Teacher Training in Poland. Changes in Poland, the Implications for Education. Institute for Educational Research, Warsaw, Poland.

Pendel, A. Y. (2003). Management of Educational Institutions in Poland: Status and Prospects for Development. Extended abstract of candidate's thesis. Lviv, Ukraine. 